Original article

\title{
COVID-19 and recurrent respiratory infections in children of Kazakhstan
}

\author{
Adil Zhamankulov ${ }^{1,2}$, Rafail Rozenson ${ }^{2}$, Marina Morenko ${ }^{2}$, Kseniya Shnayder ${ }^{2}$, Ulzhan Akhmetova ${ }^{2}$, Alina Tyo ${ }^{2}$ \\ ${ }^{1}$ Astana Medical University, Nur-Sultan, Kazakhstan \\ 2 University Medical Center, Nur-Sultan, Kazakhstan
}

Received 18 November 2020, Revised 2 February 2021, Accepted 24 February 2021

(C) 2020, Zhamankulov A., Rozenson R., Morenko M., Shnayder K., Akhmetova U., Tyo A.

(C) 2020, Russian Open Medical Journal

Abstract: The study goal was to investigate the COVID-19 clinical course in children with recurrent respiratory infections (RRI) in NurSultan, Kazakhstan.

Material and Methods - we conducted the retrospective analysis of 94 children with RRI, diagnosed with COVID-19, in Nur-Sultan, Kazakhstan. The study involved 53 males and 41 females. The inclusion criterion for the study was the frequency of RRI at least six times per year. In the course of our study, we split the patients among three groups and identified two phenotypes. These groups included children with RRI and atopic phenotype (Group 1), with D-deficiency phenotype (Group 2), and control group (Group 3) encompassing children with RRI lacking these phenotypes.

Results - The most common symptoms of 94 pediatric patients were dry cough (94.7\%), fever (81.9\%), along with a loss of appetite and fatigue (76.6\%). Malaise was observed in $74.5 \%$ cases, rhinorrhea was noted in $71.2 \%$ of patients, sore throat was detected in $64.9 \%$ of children, and dyspnea was established in $45.7 \%$ of cases. We observed no statistical differences in clinical manifestations of COVID-19 among three groups of children. However, duration of hospitalization period, of fever, and of the catarrhal period differed significantly among the groups $(p<0.001)$.

Conclusion - In children with RRI and vitamin D deficiency, who were diagnosed with COVID-19, the course of the infection was unfavorable (which was confirmed by a longer hospital stay and catarrhal period), and a more severe intoxication syndrome was observed. In the group of children with atopic phenotype, a prolonged residual cough was detected.

Keywords: COVID-19, children, symptoms, recurrent respiratory infections.

Cite as Zhamankulov A, Rozenson R, Morenko M, Shnayder K, Akhmetova U, Tyo A. COVID-19 and recurrent respiratory infections in children of Kazakhstan. Russian Open Medical Journal 2021; 10: e0104.

Correspondence to Adil Zhamankulov. E-mail: kazzzah@mail.ru.

\section{Introduction}

At the end of December 2019, 41 cases of pneumonia of unknown origin had been registered in Wuhan city of Hubei province, China, which have led to the development of SARS. The investigation had uncovered a new type of coronavirus, SARS-CoV-2, which have caused the pandemic. Extremely crowded Huanan seafood market have been considered the nidus of this coronavirus infection [1, 2]. The Research Group of International Committee on Taxonomy of Viruses had specified this new coronavirus as SARSCoV-2, and World Health Organization (WHO) has named this coronavirus infection COVID-19 [3, 4]. Due to rapid spread of SARSCoV-2 infection worldwide, WHO has announced the pandemic of COVID-19 on March 11, 2020 [5].

The Republic of Kazakhstan is located in Central Asia and has borders with Russia, China, Kyrgyzstan, Uzbekistan and Turkmenistan. The first case of COVID-19 was registered here on March 13, 2020. On March 22, 2020, the Government adopted strict quarantine measures. Consequently, big cities of Kazakhstan have been closed. According to official data, at the time of the manuscript preparation, 187,970 confirmed COVID-19 cases,
168,768 treated cases and 2,556 deaths have been registered in Kazakhstan from the very beginning of the pandemic [6].

The first case of COVID-19 infection among children was described in January, 2020, in Shenzhen, China [7]. Epidemiological data from numerous publications have indicated that SARS-CoV-2 infection course in children was less severe than in adults, unless there were serious comorbidities [8]. Furthermore, according to the results of another Chinese study of 2,143 children, the COVID-19 infection course was mild in most patients, while severe cases were observed just in $5.9 \%$ of infected children. As for adult patients, the severe course of COVID-19 infection was registered in 18.5\% [9].

Fever and cough were the most frequently observed clinical symptoms in children [4]. Another study has reported that cough was present in $48.5 \%$ of patients, pharyngeal erythema was observed in $46.2 \%$, fever was detected in $41.5 \%$, tachypnea was noted in $28.7 \%$, whereas diarrhea and nasal congestion were established in just $10 \%$ of those [10]. Regarding adult patients, most common clinical signs were fever (98.6\%), fatigue (69.6\%), dry cough (59.4\%) [11], and shortness of breath (31\%) [12].

When diagnosing SARS-CoV-2 infection in children, taking a thorough medical history, conducting accurate physical 
examination, PCR and other laboratory tests are recommended. In blood test, increase or decrease of leukocytes and lymphocytes may be observed, while in biochemical test, increased levels of Creactive protein, procalcitonin, and liver enzymes may be registered. The X-ray findings may include the signs of unilateral or bilateral infiltrative pneumonia. On CT scan of lungs, such sign as ground-glass opacities may be detected $[13,14]$.

Study goal: to investigate the clinical course of coronavirus infection in children with recurrent respiratory infections.

\section{Material and Methods}

\section{Study design and participants}

The retrospective analysis of 94 children at the age of 3-17 years old with recurrent respiratory infections (RRI), who were diagnosed with COVID-19 and had a positive family history of SARS-CoV-2 infection, was conducted. In such children, real-time reverse transcription polymerase chain reaction (RT-PCR) was conducted for COVID-19 confirmation. All children were admitted to the Division of Pulmonary Care Medicine at the City of NurSultan Children's Hospital from June 1 to August 28, 2020. The study involved 53 males and 41 females.

\section{Inclusion and exclusion criterio}

The inclusion criteria incorporated the frequency of RRI at least six times per year; absence of comorbidities (endocrine disorders, congenital malformations, oncological diseases); under 18 years old; positive PCR test for COVID-19; parental consent, and informed consent of patients. The exclusion criteria encompassed chronic foci of ENT pathology (e.g., chronic sinusitis, pharyngitis) and primary immunodeficiencies.

\section{Epidemiological characteristics and procedures}

Children were more often infected from their family members. On the first day of hospitalization, all children underwent PCR test for COVID-19. To identify SARS-CoV-2 RNA, the sample was scraped off the posterior wall of the laryngeal cavity, using a cotton swab, which was then placed in the solution for virus preservation. The sample was transported at a temperature of $2-8^{\circ} \mathrm{C}$ to the specialized facility, following the rules listed in the Sanitary and Epidemiological Requirements for Laboratories Using Potentially Hazardous Chemical and Biological Substances of November 14, 2017, No. 15990. The analysis for the viral RNA detection was carried out on an automated analyzer Tianlong (China) within 24 hours.

\section{Examination of patients}

At the hospital, a complete clinical examination, along with thorough collection of clinical and epidemiological (the quarantine regimen was introduced in Kazakhstan) anamnesis was carried out. Furthermore, first-level examination including complete blood count, urinalysis and biochemistry test were conducted. The latter included identifying the content of C-reactive protein, creatinine, glucose, chloride, blood urea nitrogen, bilirubin, aspartate aminotransferase, alanine aminotransferase, total protein, electrolytes level (total calcium, potassium, sodium). Besides, blood coagulation profile and additional laboratory tests (such as lactate dehydrogenase, procalcitonin, vitamin $\mathrm{D}$, and $\mathrm{IgE}$ ) were performed, if prescribed by physicians. Some patients underwent chest X-ray, computed tomography, abdominal ultrasound, kidney ultrasound, ECHO-cardiography, and ECG. Laboratory test was performed at least once in five days; some children were tested more frequently, if necessary (based on the course of the disease). Discharge criteria for pediatric patients were improvement of clinical and laboratory data, and negative PCR test for COVID-19.

\section{Statistical analysis}

Data processing and compilation of tables was performed using Microsoft ${ }^{\circledR}$ Excel 2010 for Windows. For statistical data processing, the statistical software package Jamovi (version 1.2.27.0; www.jamovi.org) was used. The tables present clinical manifestations, gender, age, values of basic laboratory parameters and their percentages. Normally distributed variables were presented using means \pm standard deviations, whereas for non-normally distributed variables, medians were used. For quantitative indicators, the one-way ANOVA test (Kruskal-Wallis test) was conducted regardless of the normal distribution. The chisquare test was employed for qualitative traits. Parameter values with $p<0.05$ were considered statistically significant.

\section{Results}

\section{Demographics and study groups}

Our retrospective study involved 94 patients (age range: 3-17 years old, average age and SD: $5.9 \pm 3.4$ ). The average duration of a hospital stay was $8.4 \pm 2.8$ days.

Among all observed children, 31 (33.0\%) had history of allergy (total IgE $>100 \mathrm{U} / \mathrm{ml}$, a history of food allergy, hives, or seasonal hay fever). Deficiency of the vitamin D was detected in 28 (29.8\%) patients $(25(\mathrm{OH}) \mathrm{D}<20 \mathrm{ng} / \mathrm{L})$. In 35 (37.2\%) patients (control group), those parameters were within normal ranges. That is why we split patients among three groups and compared the course of COVID-19 among the groups: children with RRI and atopic phenotype (Group 1), with D-deficiency phenotype (Group 2) and control group (Group 3) encompassing children with RRI lacking these phenotypes (Figure 1).

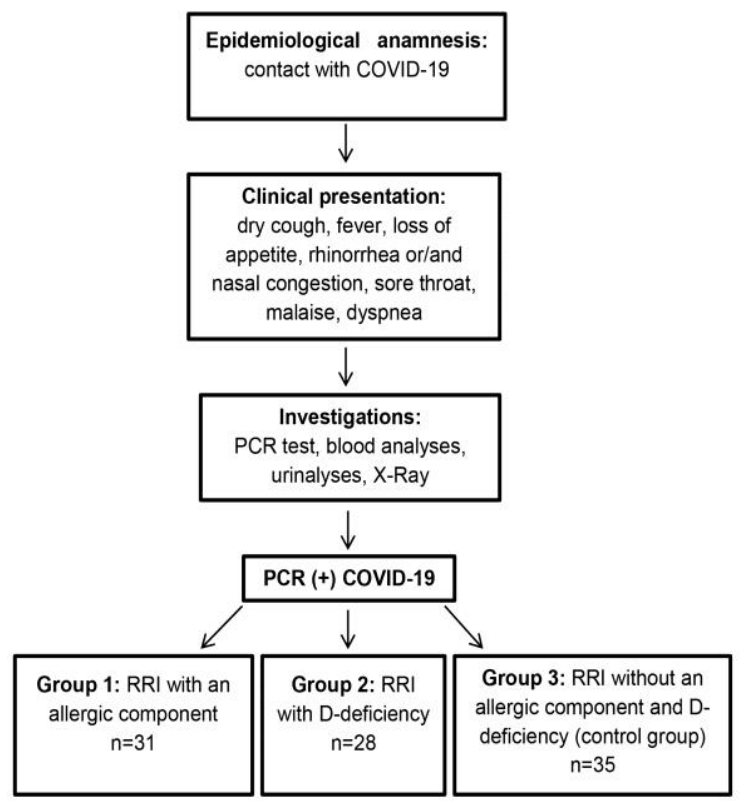

Figure 1. The research process. 
Table 1. Clinical manifestations of COVID-19 in children with RRI at the time of hospital admission in Nur-Sultan, Kazakhstan

\begin{tabular}{|c|c|c|c|c|}
\hline \multirow{2}{*}{ Characteristics } & \multicolumn{3}{|c|}{ COVID-19 } & \multirow[b]{2}{*}{$p$} \\
\hline & Group 1 & Group 2 & Group 3 & \\
\hline Number of patients & $\mathrm{n}=31$ & $\mathrm{n}=28$ & $\mathrm{n}=35$ & \\
\hline \multicolumn{5}{|l|}{ Gender: } \\
\hline Male & $18 / 31(58.1 \%)$ & $19 / 28(67.9 \%)$ & $16 / 35(45.7 \%)$ & 0.216 \\
\hline Female & $13 / 31(41.9 \%)$ & $9 / 28(32.1 \%)$ & $19 / 35(54.3 \%)$ & \\
\hline Age (years) Mean (SD) & $6.4 \pm 3.8$ & $5.8 \pm 3.3$ & $5.4 \pm 3.2$ & 0.687 \\
\hline \multicolumn{5}{|l|}{ Clinical symptoms: } \\
\hline Dry cough & $29(93.5 \%)$ & $27(96.4 \%)$ & $33(94.2 \%)$ & 0.878 \\
\hline Fever & $24(77.4 \%)$ & $27(96.4 \%)$ & $26(74.2 \%)$ & 0.056 \\
\hline Loss of appetite & $25(80.6 \%)$ & $24(85.7 \%)$ & $23(65.7 \%)$ & 0.143 \\
\hline Fatigue & $25(80.6 \%)$ & $24(85.7 \%)$ & $23(65.7 \%)$ & 0.238 \\
\hline Malaise & $21(67.7 \%)$ & $24(85.7 \%)$ & $25(71.4 \%)$ & 0.250 \\
\hline Rhinorrhea / Nasal congestion & $21(67.7 \%)$ & $20(71.4 \%)$ & $26(74.2 \%)$ & 0.678 \\
\hline \multicolumn{5}{|l|}{ Sore throat } \\
\hline Dyspnea & $20(64.5 \%)$ & 19(67.9\%) & $22(62.9 \%)$ & 0.887 \\
\hline Vomiting / Nausea & $14(45.1 \%)$ & $16(57.1 \%)$ & $13(37.1 \%)$ & 0.285 \\
\hline \multirow[t]{2}{*}{ Diarrhea } & $3(9.7 \%)$ & $4(14.3 \%)$ & $2(5.7 \%)$ & 0.517 \\
\hline & $2(6.5 \%)$ & $4(14.3 \%)$ & $1(2.9 \%)$ & 0.222 \\
\hline \multicolumn{5}{|l|}{ Duration (days) of: } \\
\hline Hospital stay & $7 \pm 0.9$ & $12.3 \pm 1.5$ & $6.3 \pm 0.7$ & $<0.001$ \\
\hline Fever & $4.8 \pm 0.7$ & $5.7 \pm 0.7$ & $4.2 \pm 0.7$ & $<0.001$ \\
\hline Catarrhal period & $5.7 \pm 0.9$ & $7.3 \pm 1.3$ & $5.1 \pm 0.8$ & $<0.001$ \\
\hline
\end{tabular}

Table2. Results of laboratory and instrumental tests in children with COVID-19 at the time of hospital admission

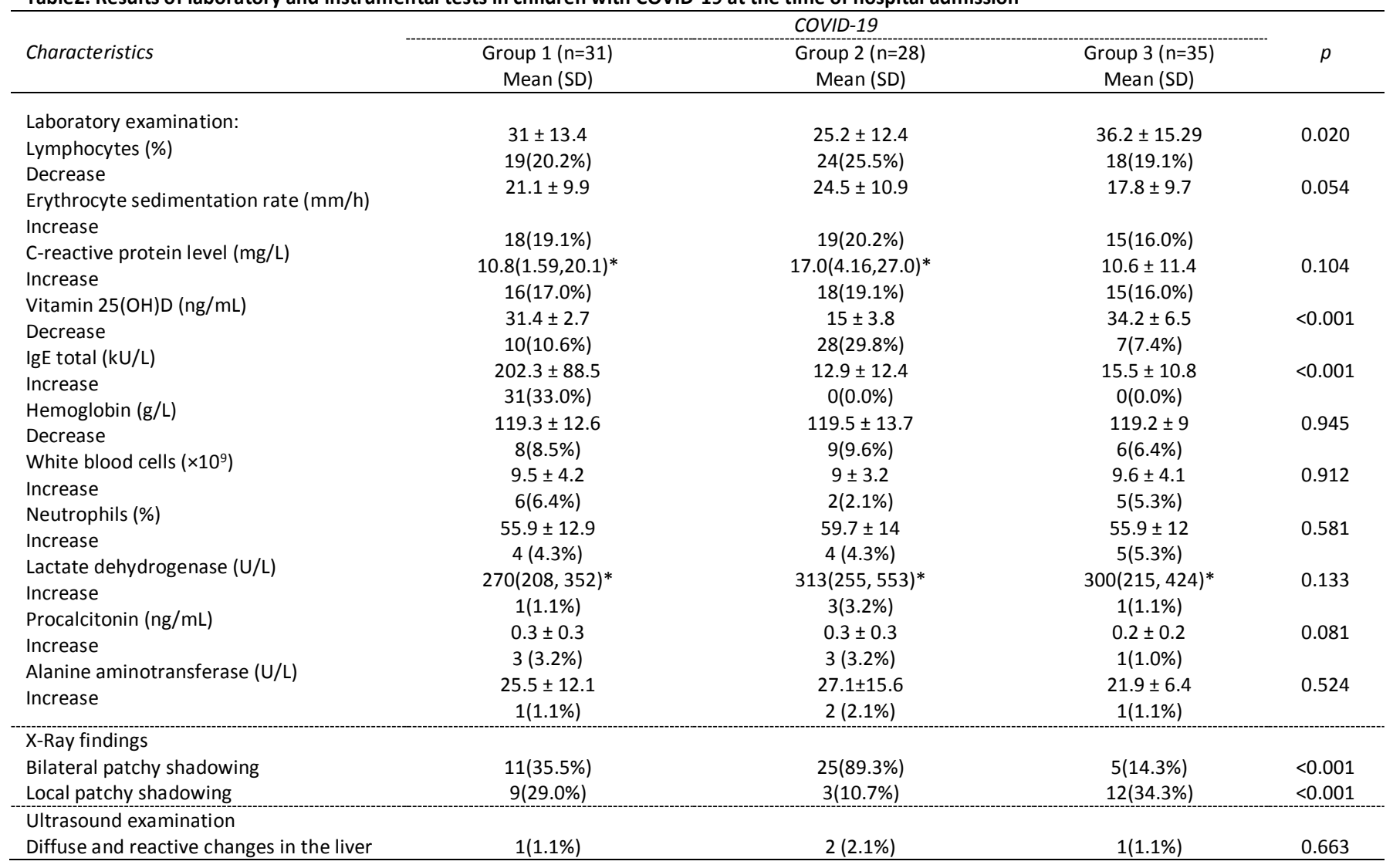

The table includes solely changed parameters as identified by laboratory analyses. The normal range and standard values sensu Pediatric Laboratory Values [15]. * For these averages, medians with lower and upper quartile values were used, since the distributions of these parameters were not normal: Me (LQ, UQ). 

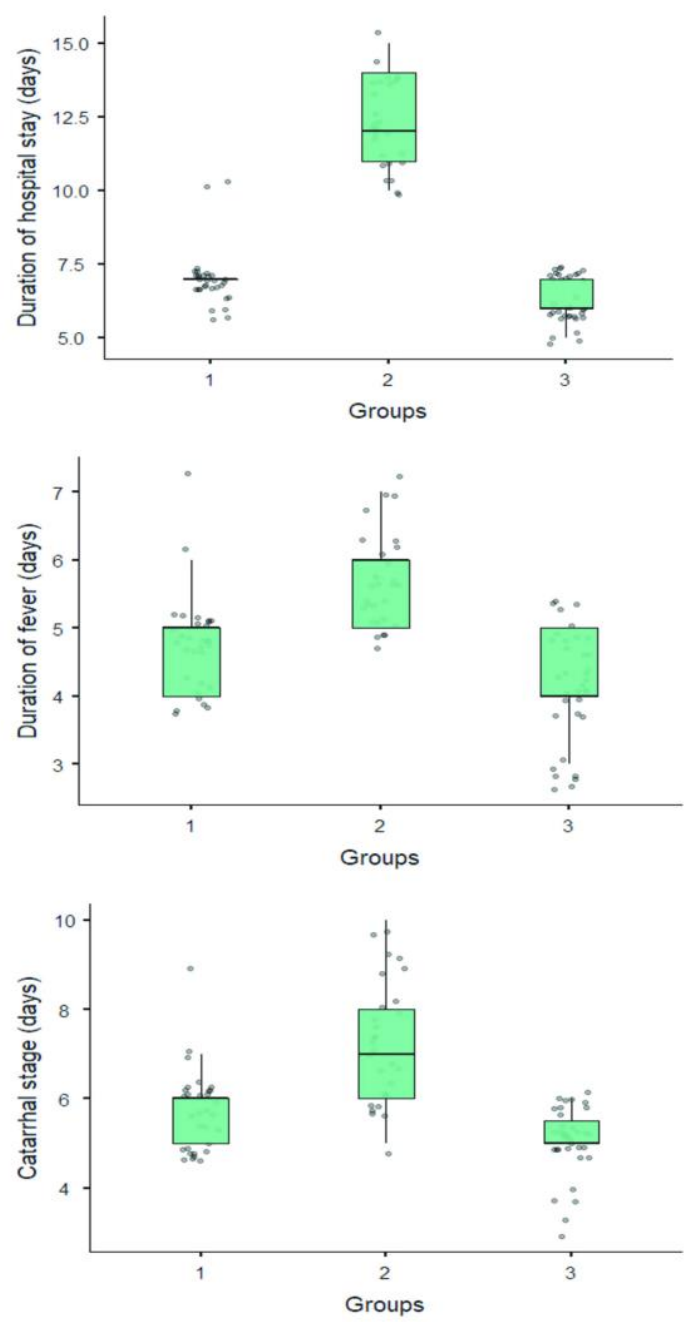

Figure 2. Length of hospital, febrile and catarrhal periods in three groups.

\section{Clinical manifestations}

The main clinical signs of COVID-19 in children with RRI in three groups were dry cough ( $n=89 ; 94.7 \%)$, fever $(n=77 ; 81.9 \%)$, loss of appetite $(n=72 ; 76.6 \%)$, fatigue $(n=72 ; 76.6 \%)$, malaise $(n=70 ; 74.5 \%)$, rhinorrhea and/or nasal congestion $(n=67 ; 71.2 \%)$, and sore throat ( $n=61 ; 64.9 \%)$. No statistical significance was found for clinical manifestations among the groups. (Table 1 ).

\section{Duration of intoxication period and hospitalization}

The duration of a hospital stay for children in Group 2 was longer (12.3 \pm 1.5$)$ versus Group $1(7 \pm 0.9)$ and Group $3(6.3 \pm 0.7)$. The number of fever days for children varied among groups (Group $2=5.7 \pm 0.7$, Group $1=4.8 \pm 0.7$, and Group $3=4.2 \pm 0.7(p<0.001)$. Children with vitamin $D$ deficiency had prolonged catarrhal period (7.3 \pm 1.3 days). In children with allergy, the catarrhal period lasted $5.7 \pm 0.9$ days, while in control group, it was $5.1 \pm 0.8$ days (Figure 2 ). In the group of children with atopic phenotype, a prolonged residual cough was observed.

The prolonged duration of clinical manifestations and hospital stay was most likely due to the fact that, in children with vitamin $D$ deficiency, bilateral pneumonia was detected more often via X-ray examination (in $89.3 \%$ of cases) than in children with atopy (in $35.5 \%$ ), or control group (in $14.3 \%$ ). Obstructive bronchitis was identified in 11 patients (11.7\%), and pneumonia was observed in 64.5\% patients with atopic phenotype and RRI: right-sided focal lower lobe pneumonia (in 9 children; 29.0\%), and bilateral lower lobe pneumonia $(n=11 ; 35.5 \%)$. As seen in Figure 3,2 patients had asymptomatic course of COVID-19 in the control group (5.7\%); COVID-19 infection proceeded in the form of acute respiratory infection in 16 patients (45.7\%); and in $48.6 \%$ patients, the infection progressed in the form of community-acquired pneumonia: right-sided focal lower lobe pneumonia $(n=12 ; 34.3 \%)$, and bilateral lower lobe pneumonia $(n=5 ; 14.3 \%)$.

\section{Laboratory analyses}

According to the laboratory results summarized in Table 2, no statistically significant differences were found between the study groups on any laboratory parameters, except for lymphopenia (Group $1=20.2 \%$, Group $2=25.5 \%$, and Group $3=19.1 \%$; $\mathrm{p}=0.020)$. Vitamin $D$ deficiency $(<20 \mathrm{ng} / \mathrm{L})$ was detected solely in Group 2 (29.8\%), while in Group 1 and Group 3, we observed its insufficient levels $(<30 \mathrm{ng} / \mathrm{L}$ in $18.0 \%(p<0.001)$. Increased IgE was observed only in Group 1, while in other groups its content was within the normal reference range $(p<0.001)$ (Table 2).

\section{Diagnostic radiology}

On the chest X-ray, community-acquired bilateral pneumonia was detected more often in Group 2 (89.3\%), compared with Group $1(35.5 \%)$ and Group $3(14.3 \%)(p<0.001)$. Ultrasound examination of the abdominal cavity and kidneys revealed no differences. On the echocardiogram and ECG, the contractile function of heart ventricles was satisfactory: no changes were detected (Table 2).

\section{Discussion}

In Kazakhstan, from March 16 until May 11, 2020, a state of emergency was introduced because of the threat of coronavirus infection spread, with a gradual weakening of quarantine measures, depending on epidemiological situation in the country. Various measures were taken to reduce the spread of coronavirus infection, such as social distancing, school and kindergarten closures, closures of potentially crowded businesses, teleworking, and restrictions on entering and exiting the country [16].

Children were more frequently infected from their family members with confirmed COVID-19 infection. SARS-CoV-2 has been causing high prevalence of pneumonia in infected individuals. According to the systematic review of 46 clinical cases of COVID-19 in children, the main manifestations of this infection were fever (64\%), cough (35\%), and rhinorrhea (16\%). An asymptomatic course $(15 \%)$ was characteristic for $15 \%$ of children. On X-ray, ground-glass opacities were detected (54\%). Laboratory analyses implied lymphopenia (33\%), augmented D-dimer (52\%) and C-reactive protein (40\%) [17].

In most cases, children had asymptomatic or mild course of COVID-19 infection. This may be explained by the lower number of angiotensin-converting enzyme type 2 receptors in children (ACE2 is abundantly expressed in the cells of the respiratory tract), compared with adults. SARS-CoV enters the host cells through ACE2 receptors $[18,19]$. 


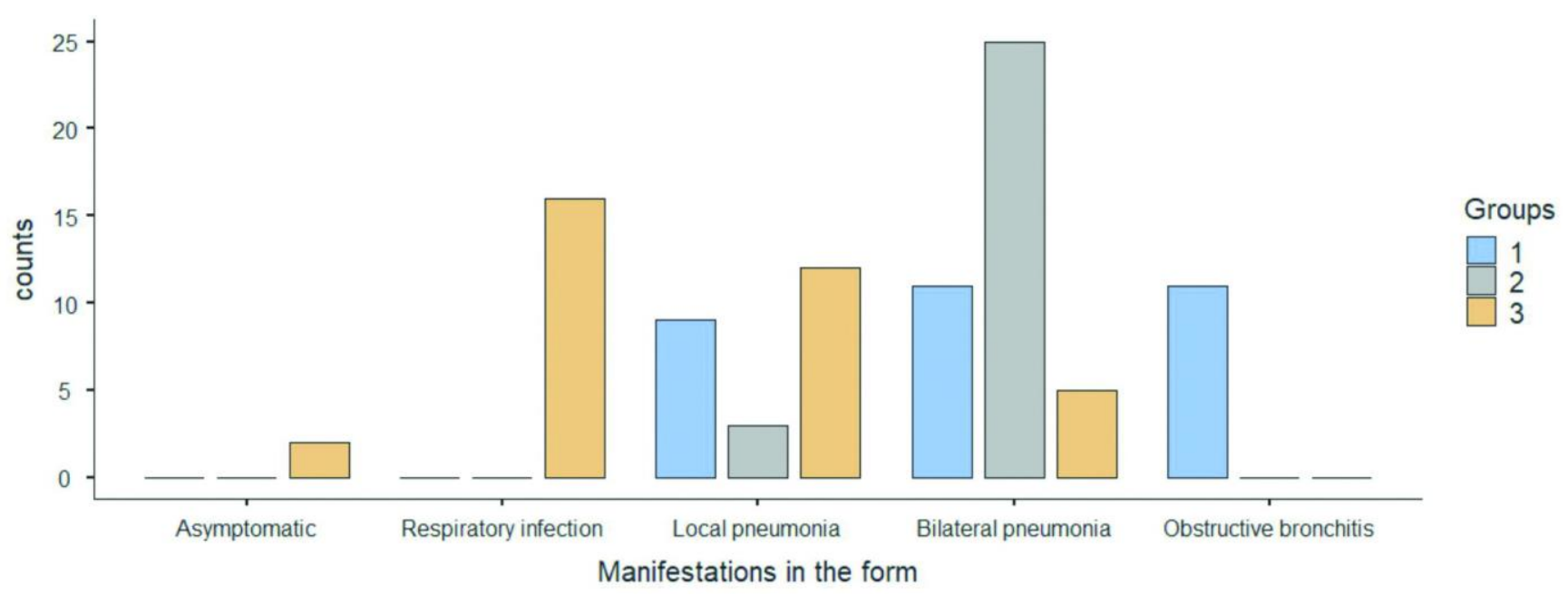

Figure 3. This bar plot represents manifestation of COVID-19 in children with RRI.

During our research, we identified a group of children with RRI, since that group was the most common in the child population and was more susceptible to various infectious diseases. As frequent respiratory diseases contribute to the formation of chronic foci of infection, the body immunological resistance, adaptive defense mechanisms, and immunobiological protective barriers weaken. The combination of mixed infections may lead to more severe virus-induced immune dysfunction, which could trigger further recurrences of respiratory infections [20].

Currently, there are some published studies regarding the severity of COVID-19 in children with vitamin D deficiency [21, 22], as there is a relationship between vitamin $D$ and the immune response in conditions of various infections [23, 24]. Furthermore, the specific data exist regarding the severity of COVID-19 course in patients with allergy. It has been noted that such patients had milder course of coronavirus infection, and therefore, their lungs were affected to a lesser extent. One of the possible causes of this finding is related to less pronounced damage of $T$ cells in such patients [25]. Also, it is thought that allergy is not a risk factor for severity of COVID-19 in children [26]. Another explanation of this pattern is that children with atopic phenotype (for example, in the form of bronchial asthma) are less likely to suffer from severe course of COVID-19, since inhaled steroids are used in its therapy [27].

Our monocenter retrospective study investigated the clinical and laboratory manifestations of COVID-19 in frequently ill children. We discovered no significant differences among the symptoms of coronavirus infection in our study versus global experience regarding COVID-19 in children. It should be noted that during the follow-up, children with vitamin D deficiency had a longer recovery stage and prolonged presence of pneumonia, compared with other groups, while there was a longer residual cough after recovery in the group of children with atopy.

\section{Conclusion}

During the observation period for patients with RRI, there were no deaths in any group, and the following phenotypes were identified: atopic and D-deficient. An unfavorable course of COVID19 in the form of longer hospital stay and catarrhal period, as well as higher severity of intoxication, was revealed in a D-deficient group of patients infected with coronavirus. However, in the group of children with atopic phenotype, a prolonged period of residual cough was detected. It is possible that these etiological factors (vitamin D deficiency and allergy symptoms) could affect the severity and duration of coronavirus infection in children with RRI. Further, more thorough, study is needed to confirm this hypothesis.

\section{Conflict of interest}

The authors declare no conflicts of interest.

\section{Ethical approval}

The study was approved by the Ethics Committee: Protocol No. 2020.3.7, which was signed by the Local Bioethics Committee at Astana Medical University. The authors complied with the ethical principles of the Declaration of Helsinki, World Medical Association. The informed consent of the patients was taken from all study participants.

\section{Funding}

This research received no external funding.

\section{References}

1. Lu H, Stratton CW, Tang YW. Outbreak of pneumonia of unknown etiology in Wuhan, China: The mystery and the miracle. J Med Virol 2020; 92(4): 401-402. https://doi.org/10.1002/imv.25678.

2. Zhu N, Zhang D, Wang W, Li X, Yang B, Song J, et al. A novel coronavirus from patients with pneumonia in China, 2019. N Engl J Med 2020; 382(8): 727-733. https://doi.org/10.1056/NEJMoa2001017.

3. Coronaviridae Study Group of the International Committee on Taxonomy of Viruses. The species Severe acute respiratory syndromerelated coronavirus: classifying 2019-nCoV and naming it SARS-CoV-2. Nat Microbiol 2020; 5(4): 536-544. https://doi.org/10.1038\%2Fs41564020-0695-z.

4. She J, Liu L, Liu W. COVID-19 epidemic: Disease characteristics in children. J Med Virol 2020; 92(7): 747-754. https://doi.org/10.1002/jmv.25807.

5. Cucinotta D, Vanelli M. WHO declares COVID-19 a pandemic. Acto Biomed 2020; 91(1): 157-160 https://doi.org/10.23750/abm.v91i1.9397.

6. Coronavirus 2020 Kazakhstan. https://coronavirus2020.kz. 
7. Chan JF, Yuan S, Kok KH, To KK, Chu H, Yang J, et al. A familial cluster of pneumonia associated with the 2019 novel coronavirus indicating person-to-person transmission: A study of a family cluster. Lancet 2020; 395(10223): 514-523. https://doi.org/10.1016/S01406736(20)30154-9.

8. Barton M, Mehta K, Kumar K, Lu J, Le Saux N, Sampson M, et al. COVID-19 Infection in children: Estimating pediatric morbidity and mortality. MedRxiv. The preprint server for health sciences 2020: 1-26. https://doi.org/10.1101/2020.05.05.20091751.

9. Parri N, Lenge M, Buonsenso D. Children with COVID-19 in pediatric emergency departments in Italy. N Engl J Med 2020; 383(2): 187-190. https://doi.org/10.1056/NEJMc2007617.

10. Alsayed R, Kadhom M, Yousif E, Sabir DK. An epidemiological characteristic of the COVID-19 among children. Lett Appl NanoBioScience 2020; 9(3): 1156-1164. https://doi.org/10.33263/LIANBS93.11561164.

11. Wang D, Hu B, Hu C, Zhu F, Liu X, Zhang J, et al. Clinical characteristics of 138 hospitalized patients with 2019 novel coronavirus-infected pneumonia in Wuhan, China. JAMA 2020; 323(11): 1061-1069. https://doi.org/10.1001/jama.2020.1585.

12. Chen N, Zhou M, Dong X, Qu J, Gong F, Han Y, et al. Epidemiological and clinical characteristics of 99 cases of 2019 novel coronavirus pneumonia in Wuhan, China: A descriptive study. Lancet 2020; 395(10223): 507-513. https://doi.org/10.1016/S0140-6736(20)302117.

13. Zimmermann $P$, Curtis N. COVID-19 in Children, Pregnancy and Neonates: A review of epidemiologic and clinical features. Pediatr Infect Dis J 2020; 39(6): 469-477. https://doi.org/10.1097/INF.0000000000002700.

14. Xia W, Shao J, Guo Y, Peng X, Li Z, Hu D. Clinical and CT features in pediatric patients with COVID-19 infection: Different points from adults. Pediatr Pulmonol 2020; 55(5): 1169-1174. https://doi.org/10.1002/ppul.24718.

15. Andropoulos DB. Appendix B. Pediatric Normal Laboratory Values. In: Gregory's Pediatric Anesthesia. Gregory GA, Andropoulos DB, eds. 5th Ed. Blackwell Publishing Ltd 2012: 1300-1314. https://doi.org/10.1002/9781444345186.app2.

16. Maukayeva S, Tokayeva A, Issabekova Z, Kiyebayeva A, Karimova S. COVID-19 in Kazakhstan: A fatal case report. Erciyes Med J 2020; 42(4): 483-485. https://doi.org/10.14744/etd.2020.37630.

17. Yasuhara J, Kuno T, Takagi H, Sumitomo N. Clinical characteristics of COVID-19 in children: A systematic review. Pediatr Pulmonol 2020; 55(10): 2565-2575. https://doi.org/10.1002/ppul.24991.

18. Xu H, Zhong L, Deng J, Peng J, Dan H, Zeng X, et al. High expression of ACE2 receptor of 2019-nCoV on the epithelial cells of oral mucosa. Int $J$ Oral Sci 2020; 12(1): 1-5. https://doi.org/10.1038/s41368-020-0074-x.

19. Jia HP, Look DC, Shi L, Hickey M, Pewe L, Netland J, et al. ACE2 receptor expression and severe acute respiratory syndrome coronavirus infection depend on differentiation of human airway epithelia. J Virol 2005; 79(23): 14614-14621. https://doi.org/10.1128/jvi.79.23.14614-14621.2005.

20. de Martino $M$, Ballotti $S$. The child with recurrent respiratory infections: Normal or not? Pediatr Allergy Immunol 2007;18 Suppl 18: 13-18. https://doi.org/10.1111/i.1399-3038.2007.00625.x.

21. Grant WB, Lahore H, McDonnell SL, Baggerly CA, French CB, Aliano JL, et al. Evidence that vitamin $D$ supplementation could reduce risk of influenza and COVID-19 infections and deaths. Nutrients 2020; 12(4): 1-19. https://doi.org/10.3390/nu12040988.

22. Panfili FM, Roversi M, D’Argenio $P$, Rossi $P$, Cappa $M$, Fintini D. Possible role of vitamin $D$ in COVID-19 infection in pediatric population. J Endocrinol Invest 2020; 44(1): 27-35. https://doi.org/10.1007/s40618-020-01327-0.

23. Holick MF, Binkley NC, Bischoff-Ferrari HA, Gordon CM, Hanley DA, Heaney RP, et al. Evaluation, treatment, and prevention of vitamin D deficiency: An endocrine society clinical practice guideline. J Clin
Endocrinol Metab 2011; 96(7): 1911-1930. https://doi.org/10.1210/jc.2011-0385.

24. Bergman $P$, Norlin AC, Hansen $S$, Rekha RS, Agerberth B, BjörkhemBergman L, et al. Vitamin D3 supplementation in patients with frequent respiratory tract infections: A randomized and double-blind intervention study. BMJ Open 2012; 2(6): e001663. https://doi.org/10.1136/bmjopen-2012-001663.

25. Shi W, Gao Z, Ding Y, Zhu T, Zhang W, Xu Y. Clinical characteristics of COVID-19 patients combined with allergy. Allergy 2020; 75(9): 24052408. https://doi.org/10.1111/all.14434.

26. Du $H$, Dong $X$, Zhang JJ, Cao $Y Y$, Akdis $M$, Huang $P Q$, et al. Clinical characteristics of 182 pediatric COVID-19 patients with different severities and allergic status. Allergy 2021; 76(2): 510-532. https://doi.org/10.1111/all.14452.

27. Peters MC, Sajuthi S, Deford P, Christenson S, Rios CL, Montgomery $M T$, et al. COVID-19-related genes in sputum cells in asthma: Relationship to demographic features and corticosteroids. Am J Respir Crit Care Med 2020; 202(1): 83-90. https://doi.org/10.1164/rccm.202003-08210C.

\section{Authors:}

Adil Zhamankulov - PhD student, Department of Childhood Diseases with Specialization in Allergology, Hematology and Endocrinology, Astana Medical University; Department of Pediatrics, National Research Center for Maternal and Child Health, University Medical Center, Nur-Sultan, Kazakhstan. https://orcid.org/0000-0002-9928-0617.

Rafail Rozenson - MD, DSc, Professor, Department of Childhood Diseases with Specialization in Allergology, Hematology and Endocrinology, Astana Medical University, Nur-Sultan, Kazakhstan. https://orcid.org/0000-00016088-2269.

Marina Morenko - MD, DSc, Professor, Chair of the Department of Childhood Diseases with Specialization in Allergology, Hematology and Endocrinology, Astana Medical University, Nur-Sultan, Kazakhstan. https://orcid.org/0000-0001-9553-3560.

Kseniya Shnayder - PhD, Associate Professor, Department of Childhood Diseases with Specialization in Allergology, Hematology and Endocrinology, Astana Medical University, Nur-Sultan, Kazakhstan https://orcid.org/00000002-4919-1878

Ulzhan Akhmetova - Assistant, Department of Childhood Diseases with Specialization in Allergology, Hematology and Endocrinology, Astana Medical University, Nur-Sultan, Kazakhstan. https://orcid.org/0000-00031656-5578.

Alina Tyo - Assistant, Department of Childhood Diseases with Specialization in Allergology, Hematology and Endocrinology, Astana Medical University, Nur-Sultan, Kazakhstan. https://orcid.org/0000-00021467-6699. 